\title{
Catch them young: grooming a new generation of physicians in India
}

\author{
Anamitra Barik $^{1,2} \cdot$ Rajesh Kumar Rai ${ }^{1}$
}

Received: 17 February 2017 / Accepted: 6 June 2017 / Published online: 23 June 2017

(C) Springer-Verlag GmbH Germany 2017

\begin{abstract}
Aim Physicians are often accused of (un)intended medical malpractice, which is linked with their economic stimulus in one way or another. To disentangle the motivation behind this claim, this article digs into India's existing medical training and the motivation of young graduates to practice medicine. Subjects and methods A narrative review was conducted by retrieving the existing literature from various sources.

Results To a medical education aspirant, a doctor is perceived as someone who earns his or her daily living independently. Usually they become very rich, and popularity comes with the package. With this motivation, some clinicians come out of medical college failing to adopt ethical medical practices.

Conclusion India demands a new generation of young aspirants who can be guided by teachers who can teach the art and philosophy of medicine, where earning limitless money is not the sole purpose of medical education.
\end{abstract}

\section{Background}

With 398 medical colleges (183 government medical colleges and 215 private ones, as in 2015), India has over 840,000 doctors to cater to its more than 1.25 billion citizens

Rajesh Kumar Rai

rajesh.iips28@gmail.com

Anamitra Barik

anomitro2010@gmail.com

1 Society for Health and Demographic Surveillance, Suri, Birbhum, West Bengal 731101, India

2 West Bengal State Department of Health and Family Welfare, Chest Clinic, Suri District Hospital, Suri, Birbhum, West Bengal 731101, India
(Reuters 2015). While India struggles to achieve the recommended doctor-population ratio (1 per 1000 population), one in every six medical colleges has been accused of cheating (according to government records and court filings) coupled with rampant fraud and unprofessional teaching practices, exacerbating the public health challenge (Reuters 2015). India produces over 45,000 doctors annually, but the training in and of itself is not a guarantee of high quality. The Former Secretary of the Ministry of Health and Family Welfare, K. Sujatha Rao, commented on the quality of doctors: "The market has been flooded with doctors so poorly trained they are little better than quacks" (Reuters 2015). India runs a healthcare system where most of the doctors participating are poorly trained in substandard medical colleges, and, to make matters worse, many recent medical graduates lack the clinical skills necessary for good patient care. This article focuses on the motivation of young people who aspire to obtain a medical degree and India's medical education discourse. It is hoped that the discussion will help to understand the motivation behind medical education in order to reevaluate the expectations of medical graduates.

\section{Aspiration, admission, and observation}

India follows rigorous guidelines for admission to medical school. To be eligible, an applicant should pass the 12th grade with a predefined score. Candidates applying to medical school generally undergo rigorous preparation when they choose to specialize in biology instead of mathematics or other sciences. The question is, where does the motivation to pursue a medical career come from when the prospective students are merely 16 years old? The obvious sources of inspiration are family members, friends, community, portrayals in films, and society at large. The advice often extended to 
potential aspirants is that either (1) doctors are able to earn a lot of money even if they do not have a fixed or permanent job, indicating a high income from the private clinical practice, or (2) doctors are accepted as people with a good reputation with a noble profession, primarily because of the belief that doctors save peoples' lives. Thus, doctors are perceived as people who earn their daily living independently, usually they become very rich, and popularity comes with the package.

With this unrealistic motivation to pursue a career in medicine comes dishonesty in the medical profession, which has undermined its core values of truth, integrity, philanthropy, and altruism, which Gorovitz and MacIntyre (1976) explained in their work on the nature of human fallibility. These two philosophers wondered why human beings fail at anything we set out to do. It starts in the medical schools where medical students observe house staff and some of their seniors recording false physical findings, and with the herd mentality prevalent in medical schools, students mindlessly inculcate this habit. House officers are often spending increasing time preparing for postgraduate or postdoctoral entrance examinations and less and less time attending to their patients. With limited access to the teaching staff, the trainees turn to house officers and their immediate seniors for instruction - a situation reminiscent of the proverb "the blind leading the blind."

In the same medical college, the newly admitted students watch the attending physician - faced with a busy schedule and unafraid of being sued by the consumer court—order a cascade of tests to be administered. If the patient's condition fails to improve or a test result is abnormal, the attending physician places the ball in the court of a band of consultants who manage different parts of the body. Money and prestige seduce some practitioners, allowing conflicts of interest to take shape, and in clinical practice the soil is particularly fertile for such conflicts. For example, physicians who own and operate specialty hospitals (Abelson 2007) have their own hightech diagnostic and therapeutic machinery (Tonelli 2007), often with the purpose of looting the patient. Nowadays, medicine based on a carefully constructed medical history coupled with an assessment of the information is obsolete. In bypassing the medical history and physical examination, the new approach moves to sophisticated tests, thus weakening the patient-doctor relationship. The brain is not applied and remains dormant indefinitely. Sometimes doctors start writing prescriptions without asking the patient a single question. There is a dictum in clinical medicine: "What the mind doesn't know, the eyes cannot see." It seems unlikely that today's physicians are taught this dictum during their medical education.

Critics argue that physicians have strong financial incentives to refer patients to their own facilities. Some physicians go around the country promoting specific drugs or biomedical devices manufactured by the companies that sponsor the trips; there are physicians who join drug company advisory boards
(Kassirer 2005) or help create industry-supported clinical practice guidelines, while others receive payments from the industry for consulting or for enrolling patients in clinical trials (Campbell et al. 2007); they pose as idols for the students. More striking is the pharmaceutical industry's subsidy of continuing medical education (Carlat 2007), including professional publications. There is strong and consistent evidence that industry-sponsored research tends to draw pro-industry conclusions; only studies with significant findings tend to be published, an observation that led Melander and colleagues to coin the phrase "evidence b(i)ased medicine" (Melander et al. 2003).

George Bernard Shaw's play, The Doctor's Dilemma (1906), concerns a physician who has discovered a cure for tuberculosis. His dilemma is that he has a limited supply of the medication and a small staff to administer it. The play talks about methods to prevent doctors from being motivated by financial gain and how to rid the medical profession of charlatans. In resource- and time-constrained settings like public hospitals where the queue is large, the quality of healthcare delivery is being compromised every day. Here the commodities physicians are struggling to ration are their time and emotional energy (Koven 2016), which are expensive indeed.

\section{Catch them young: The teacher's role}

"In medical teaching or practice, honesty is never an issue, but the emphasis on avoiding failure and achieving success" (Young 1997) in a short time span could be dangerous. Deciding whether a clinical clue is worth pursuing or should be dismissed and weighing whether a proposed test, preventive measure, or treatment entails a greater risk than the disease itself are essential judgments that a skilled clinician must make many times each day. This combination of medical knowledge, intuition, experience, and judgment defines the art of medicine (Malterud 2001), but India's medical education system is not equipped with the capability to practice the art. Healthcare delivery has become expensive, impersonal, and fragmented over the years where physicians exhibit distorted professionalism with minimal autonomy and prestige and escalating professional dissatisfaction (Zuger 2004), leading to dissatisfaction and noncompliance among patients as well as substandard medical care (Fred 2005). To make matters worse, many recent medical graduates lack the clinical skills necessary for good patient care, which is indicative of their substandard medical education (Fred 2005).

India demands a new generation of young aspirants to be guided by teachers who can teach the art and philosophy of medicine, where earning limitless money is not the sole purpose of medical education. The teachers who know and understand the pathophysiology, clinical features, natural history of diseases, and interpretation of the ordered tests should pass 
the baton on to the young people. India needs those teachers who truly comprehend the value of a good medical history and physical examination. They are the ones who have taught us to detect valvular heart disease without echocardiography, taught us to detect cyanosis by observation only, and guided us to detect splenomegaly without ultrasonography (Mukhopadhyay et al. 2013). Most importantly, they will teach us how to think. The current teachers of medicine have to recapture the Oslerian spirit (Bliss and Osler 1999):

Medicine is to be learned only by experience; it is not an inheritance; it cannot be revealed. Learn to see, learn to hear, learn to feel, learn to smell, and to know that by practice alone you can become (an) expert. Medicine is learnt by the bedside and not in classroom. Let not your conceptions of the manifestations of disease come from words heard in the lecture room or in a book. See and then reason and control. But see first. William Osler

Teachers are those who understand and believe that medicine is a calling, not an entrepreneurship. Teachers who can look at, listen to, and talk with patients are the key to lead the budding professionals to a non-reductionist approach toward patients. We need teachers who will work hard for as long as needed to ensure a patient's welfare and teachers who value a patient's priority. Inflections of voice, type of cough, facial expression, gestures, and attitude, such as body language, may reveal important clues to the meaning of the symptoms to the patient. The detection of a few scattered petechiae, a faint diastolic murmur, or a small mass in the abdomen is not a question of keener eyes and ears or more sensitive fingers but of a mind alert to those findings. Because physical findings can change with time, the physical examination should be repeated as frequently as the clinical situation warrants.

It is time to show the young aspirants the right path to the medical profession. Some doctors darkly envision a future of disengaged, intellectually lazy doctor-technicians who have made their peace with protocol-driven "cookbook" medicine with a truncated vision. Others are hopeful and believe that, despite these fears, the excellence and commitment of medical students and residents will stand out. "It is the patient who chooses the doctor," and the doctors are chosen to receive a gift of trust, which is the most precious of all (Weinberg 1995).

\section{Compliance with ethical standards}

Conflict of interest The authors declare that they have no conflict of interest.

\section{References}

Abelson R (2007) Some hospitals call 911 to save their patients. 2 April, New York Times, New York Times http://www.nytimes.com/2007/ 04/02/business/02alarm.html

Bliss M, Osler W (1999) A life in medicine. Oxford University Press, Oxford, New York

Campbell EG, Gruen RL, Mountford J, Miller LG, Cleary PD, Blumenthal D (2007) A national survey of physician-industry relationships. N Eng1 J Med 356:1742-1750

Carlat D (2007) Overdose: Industry teaches our doctors. 17 June, http:// www.houstonchronicle.com/

Fred HL (2005) Hyposkillia: deficiency of clinical skills. Tex Heart Inst J 32:255-257

Gorovitz S, Macintyre A (1976) Towards a theory of medical fallibility. J Med Philos 1:51-71

Kassirer JP (2005) On the take: how medicine's complicity with big business can endanger your health. Oxford University Press, Oxford (UK)

Koven S (2016) The doctor's new dilemma. N Engl J Med 374:608-609

Malterud K (2001) The art and science of clinical knowledge: evidence beyond measures and numbers. Lancet 358:397-400

Melander H, Ahlqvist-Rastad J, Meijer G, Beermann B (2003) Evidence b(i)ased medicine-selective reporting from studies sponsored by pharmaceutical industry: review of studies in new drug applications. BMJ 326:1171-1173

Mukhopadhyay J, Sarkar A, Chatterjee A (2013) India needs clinical not the high-tech medicine. Medicine Update 164:716-718

Reuters (2015) Special Report: Why India's medical schools are plagued with fraud. 16 June, http://www.reuters.com/article/us-indiamedicine-education-specialrepor-idUSKBN0OW1NM20150617\# 1kPT40XtQsWD1qT3.97

Tonelli MR (2007) Conflict of interest in clinical practice. Chest 132: 664-670

Weinberg RB (1995) Communion. Ann Intern Med 123:804-805

Young TA (1997) Teaching medical students to lie - the disturbing contradiction: medical ideals and the resident-selection process. CMAJ 156:219-222

Zuger A (2004) Dissatisfaction with medical practice. N Engl J Med 350: 69-75 